\title{
Empirical Structural Design for Architects, Engineers and Builders
}


For Anne

Downloaded by [] on [26/04/23]. Copyright @ ICE Publishing, all rights reserved. 


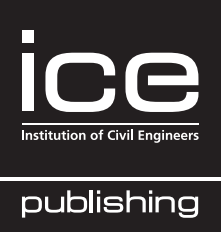

Empirical Structural Design for Architects, Engineers and Builders

\section{Thomas Boothby}

The Pennsylvania State University 
Published by ICE Publishing, One Great George Street, Westminster, London SW1P 3AA.

Full details of ICE Publishing representatives and distributors can be found at: www.icebookshop.com/bookshop_contact.asp

\section{Other titles available from ICE Publishing:}

ICE Manual of Structural Design: Buildings (2012)

J. Bull (ed.). ISBN: 978-0-7277-4144-8

Conceptual Structural Design: Bridging the Gap between Architects and Engineers, Second edition (2016)

O. Popovic Larsen. ISBN: 978-0-7277-6110-1

www.icebookshop.com

A catalogue record for this book is available from the British Library

ISBN 978-0-7277-6207-8

(C) Thomas Telford Limited 2018

ICE Publishing is a division of Thomas Telford Ltd, a wholly-owned subsidiary of the Institution of Civil Engineers (ICE).

All rights, including translation, reserved. Except as permitted by the Copyright, Designs and Patents Act 1988, no part of this publication may be reproduced, stored in a retrieval system or transmitted in any form or by any means, electronic, mechanical, photocopying or otherwise, without the prior written permission of the Publisher, ICE Publishing, One Great George Street, Westminster, London SW1P 3AA.

This book is published on the understanding that the author is solely responsible for the statements made and opinions expressed in it and that its publication does not necessarily imply that such statements and/or opinions are or reflect the views or opinions of the publishers. While every effort has been made to ensure that the statements made and the opinions expressed in this publication provide a safe and accurate guide, no liability or responsibility can be accepted in this respect by the author or publishers.

While every reasonable effort has been undertaken by the author and the publisher to acknowledge copyright on material reproduced, if there has been an oversight please contact the publisher and we will endeavour to correct this upon a reprint.

Commissioning Editor: James Hobbs

Production Editor: Madhubanti Bhattacharyya

Market Development Executive: Elizabeth Hobson

Typeset by Academic + Technical, Bristol Index created by Laurence Errington

Printed and bound in Great Britain by Latimer Trend, Plymouth 


\section{Contents}

Acknowledgements

About the author

Glossary

01

An introduction to empirical design

Reference

02

Empirical design of arches

2.1. Introduction

2.2. Load path analysis

2.3. Empirical design of arches

References

Examples

Exercises

03

\section{Empirical design of walls}

3.1. Introduction

3.2. Load paths

3.3. Empirical design of walls

3.4. Conclusion

References

Examples

Exercises

04

\section{Empirical design of columns}

4.1. Introduction

4.2. Load paths

4.3. Masonry piers

4.4. Reinforced concrete columns

4.5. Prestressed concrete columns

4.6. Steel columns

4.7. Wood columns

References

Examples

Exercises

05

\section{Empirical design of beams}

5.1. Load paths

5.2. Wood beams

5.3. Steel beams

5.4. Reinforced concrete beams

5.5. Prestressed concrete beams

References

Exercises

\section{Empirical design of trusses}

06

6.1. Wood trusses

6.2. Steel gable trusses

6.3. Steel parallel chord trusses

101

References

101

Examples

103

Exercises 
07

Empirical design of floor and roof framing systems

7.1. Steel frames

7.2. Reinforced concrete frames 114

Reference

117

Examples

08

\section{Empirical design of foundations}

8.1. Introduction

119

8.2. Types of foundations

119

Reference

125

Examples

126

Exercises

09

Empirical design of connections

135

9.1. Introduction

135

9.2. Wood

135

9.3. Steel connections 140

9.4. Concrete connections 147

9.5. Hybrid connections 148

References $\quad 149$

Examples 150

Exercises 153

$10 \ldots \ldots \ldots \ldots \ldots \ldots \ldots \ldots$ Empirical lateral systems design 157

$\begin{array}{ll}\text { 10.1. Loading } & 157\end{array}$

10.2. Empirical sizing of shear walls 161

10.3. Braced frames 165

10.4. Rigid frames 165

10.5. Multistorey frames 166

10.6. Loads normal to the surface 166

$\begin{array}{ll}\text { References } & 167\end{array}$

$\begin{array}{ll}\text { Examples } & 167\end{array}$

$\begin{array}{ll}\text { Exercises } & 175\end{array}$

$11 \ldots \ldots \ldots \ldots \ldots \ldots \ldots$ Building structural system design 179

11.1. Building occupancies 179

11.2. Preferred structural material for various occupancies 182

Reference $\quad 184$

Examples 184

$12 \ldots \ldots \ldots \ldots \ldots \ldots \ldots \ldots \ldots \ldots \ldots \ldots$ Conclusions $18 \ldots$

12.1. Range of validity of empirical design 187

12.2. When to consult an engineer 187

Reference 192

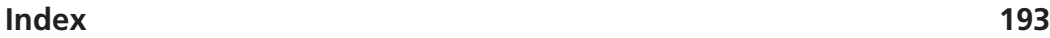

vi 
I am grateful for a number of people who have helped me to realise this book. First, to the students at The Pennsylvania State University who have allowed me to use this material in their classes to further their architectural education, and who have continued to use this material, in the form of span/ depth ratios and other rules of construction in their later coursework in architecture.

I am particularly grateful to David Klein and to Dennis Bruff for completing the illustrations in this book. Any figures not explicitly connected to others are the work of Dave and Dennis. Unattributed photographs are by the author.

I am particularly grateful to the staff of the Office of Physical Plant at The Pennsylvania State University for their willingness to allow me to use plans from their projects as examples in the book. In particular, I thank Steve Maruszewski, Craig Dubler, and Sam Bertolino.

I thank Simone Starnini for his assistance in obtaining building plans from other projects.

I especially thank James Hobbs, Madhubanti Bhattacharyya and the staff of ICE Publishing for their assistance in making this book possible.

I thank the Architecture students at Penn State University for their patience in allowing me to test this material and for their continuing interest in this way of thinking about structures. 
Downloaded by [] on [26/04/23]. Copyright @ ICE Publishing, all rights reserved. 


\section{About the author}

Thomas Boothby is Professor of Architectural Engineering at The Pennsylvania State University. He is a Registered Architect and a Professional Engineer. He has been engaged in the education of architects and architectural engineers for 26 years. He is the author of Engineering Iron and Stone: Understanding Structural Analysis and Design Methods of the Late 19th Century. 
Downloaded by [] on [26/04/23]. Copyright @ ICE Publishing, all rights reserved. 


\section{Glossary}

Abutment: A support used to resist the horizontal forces produced by an arch.

Anchorage: The connection detail between two members in which

reinforcing holds the members together, such as concrete beams attaching to columns.

Angle of embrace: The interior angle of a circular segmental arch (e.g. the angle of embrace of a semicircular arch is $180^{\circ}$ ).

Arch: A curved structure used to distribute loads over openings.

Aspect ratio: The governing ratio of a planar surface, such as length/width, width/depth, and so on.

Auger-cast pile: A foundation system in which a hole is drilled into soil and filled with reinforced concrete.

Axial force: Force acting along the longitudinal axis of a member.

Axial stress: Stress resulting from axial force.

Axis: A line of reference within a coordinate system representing a specific direction.

Backfill: Soil (or engineered fill) used to replace excavated volumes of earth.

Backing: random masonry fill added to the back of an arch

Backspan: The span adjacent to and continuous with a cantilever beam.

Bay: The area enclosed by major beams or girders.

Beam: A structural member used to carry gravity loads acting perpendicular to its axis.

Beam-column: A flexural member subject to combined axial load and bending moment.

Bearing wall: A structural wall used for the support of beams or joists.

Bedding: The mortar placed in a horizontal bed on the top of one course of masonry units.

Belled piers: A circular concrete pier that is increased in diameter at the base.

Bending moment: The internal moment within a flexural member.

Bending strength: The flexural capacity of a member (available resistance to a bending moment).

Bending stress: Stress due to a bending moment.

Bevel: A cut at an angle.

Blocking: Single cuts of dimension lumber used to brace wood joists against overturning.

Bolt: The threaded element of a connection used for fastening.

Bottom chord: The bottommost member of a truss (under typical loading conditions this is on the tension side of the truss).

Bridging: Diagonal cross-members used to brace wood or steel joists against overturning.

Buckling: The bending instability of axially loaded compression members.

Buckling stress: Critical stress required to buckle an axially loaded member.

Buttress: A structure used to support the horizontal and vertical forces produced by arches and walls.

Camber: A small, intentional increase in the level of the bottom of a beam or flat arch.

Cantilever: A beam fixed into the support at one end and free at the other end. 
Capital: An enlarged section at the top of a column used to distribute load onto column the cross-section.

Cementitious grout: A fluid comprising primarily Portland cement that cures similarly to concrete.

Centroid: The centre of gravity of a geometric shape.

Chemical grout: A viscous fluid that fills voids in soils and hardens through a curing process.

Clip angles: Short angle sections with punched bolt holes used in the connection of steel members.

CMU: See Concrete masonry unit.

Cold-formed steel: Steel shapes formed from sheet metal (commonly used for metal stud framing).

Column: A structural member (normally vertical) used to carry axial loads.

Composite construction: A method of steel construction where the beams are built integrally with the decking and slab to engage the concrete topping in compression.

Compression: The state of stress caused by two opposing inward forces.

Compression flange: The side of a flanged section that resists the compressive stress due to bending.

Concrete masonry unit (CMU): A hollow rectangular precast concrete block commonly used in the construction of walls.

Connection: The interface between two structural members.

Continuous beam: A beam spanning multiple supports.

Cope: To remove a portion of a connected steel beam web to provide clearance from the connecting beam.

Corbel: A bracket added to the exterior of a column to provide a beam bearing.

Counterfort: A stiffening member built into a cast-in-place concrete retaining wall.

Crushing: The mode of failure caused by excessive compressive stress.

Curvature: The rate of change in the slope of a member in bending.

Dead load: The load resulting from the self-weight of a structure and fixed (permanent) building components and finishes.

Deadman: A member (generally concrete or treated wood) used as a means of providing lateral support to a wall during construction or permanently.

Deep foundation: A category of foundation that includes piles, minipiles, and caissons.

Deflection: The horizontal or vertical displacement of a structure or component thereof.

Deformed steel bars: Steel reinforcing for concrete (rebar).

Density: Mass per unit volume.

Dimension lumber: Sawn lumber organised by nominal sizes.

Dome: A semi-spherical structure that distributes loads over a space.

Double-tee beam: A structural member with two webs, separated by a distance, connected by a flange (precast concrete).

Drag strut: A tension-compression member that transfers lateral force from one shear wall to another or from one part of a horizontal diaphragm to another. 
Drift: The total horizontal displacement of a storey of a building subjected to wind load.

Drilled pier: A foundation system in which soil is removed from a hole by a large-diameter auger and concrete is placed to fill this void.

Driven pile: A pile inserted by means of a series of blows.

Drop panel: The thickened portion of a concrete slab for the purposes of increasing the shear and bending capacity of the slab.

Eccentricity: The distance between a load and the centre of a cross-section. Edge beam: A beam existing at the edge of a concrete slab or deck (spandrel beam).

Effective length factor: A multiplier applied to the unbraced length of a column.

Elasticity: The ability of a material to resume its original shape after stressing.

Embedment: The depth of a reinforcing bar placed within concrete.

Engineered fill: Fill placed in shallow layers under controlled conditions of moisture content and compaction.

Engineered-wood product: A wood product assembled from components for the purposes of increasing performance.

Envelope: The enclosure of a building (thermal- and moisture-resistant skin). Equilibrium: The state of being at rest due to zero net forces.

Extrados: The upper or outer curve of an arch.

Façade: The front architectural face of a building.

Face-shell bedding: A method of placing mortar joints in concrete masonry unit walls in which only the outside and inside faces of the block are covered with mortar.

Factor of safety: A multiplier used to ensure the performance of a system. Factored loads: Loads multiplied by an overload factor as described by load cases included in the International Building Code and other building codes.

Fillet (connection between web and flange of a beam): A filled-in circular radius connection where two parts abut at right angles.

Fillet weld: A weld between two perpendicular surfaces creating a connection at the face of each object.

Fixed connection: An ideal support condition in which the end of a member is fully restrained against both translation and rotation.

Fixed-fixed: An ideal support condition in which both ends of a member (beam or column) are fully restrained against both translation and rotation.

Flange: The widened top and bottom of an I-beam, a W-shape, a channel, or other manufactured shape.

Flat plate system: A two-way concrete floor system consisting of a slab without drop panels/capitals and columns.

Flat slab system: A two-way concrete floor system consisting of slabs with drop panels/capitals and columns.

Flexible: Able to bend when subject to stresses.

Floor deck: A corrugated sheet metal panel used to support the concrete fill for a floor. 
Floor diaphragm: A structural floor used to collect and distribute lateral loads to interior lateral-load-resisting elements.

Floor slab: A structural concrete floor.

Footing: An enlarged concrete foundation support for a column or a wall.

Force intensity: The amount of force on a per unit area or length basis.

Foundation wall: A load-bearing wall (generally of concrete or concrete masonry units) subject to both axial load and bending moments, connecting the superstructure to a strip footing.

Free-body diagram: A diagram used to display forces acting on the centroid or centreline of an object.

Full bedding: A method of placing mortar joints in concrete masonry unit walls in which only the outside and the entire horizontal surface of the block are covered with mortar.

Full-penetration weld: A method of welding that involves completely filling the resulting space between two parts with weld metal.

Gable truss: A triangular-shaped truss generally for the purposes of supporting a gable roof.

Gang-nail plate: A metal plate comprising barbs on one side that is pressed onto two or more connecting wood members.

Gauge: A measure of the thickness of chords, cables, wires, and steel decking. Girder: A flexural member that supports infill beams.

Glued laminated wood (glulam): Parallel layers of wood glued and laminated so as to create one single member.

Glulam: See Glued laminated wood.

Grade: The finished ground level.

Grade beam: A beam or slab (generally concrete) spanning between concrete footings.

Gravity loads: Loads acting in the downward direction associated with dead, live, snow, and rain loads.

Ground snow load: The weight of snow associated with a specific region.

Grout: Flowable concrete fill added to the voids in concrete masonry units. Gypsum wallboard: An interior wall finish commonly known as drywall.

Headed studs: Smooth rods with a head at one end that are welded to the top of beams and girders in composite design.

Header: A member that spans over an opening in a wall.

Hollow structural shape (HSS): A hollow rectangular, square, or round structural steel tube.

Infill beams: Beams supporting floor deck within a structural bay (supported by girders).

Internal shear: The shear force within a member.

Inverted tee: A structure usually made of concrete in the shape of an upside-down capital $\mathrm{T}$ so as to be able to support connecting members from either side.

Isolated spread footing: A rectangular or square foundation supporting a single column. 
Jack arch: A method of spanning an opening in masonry construction, where the underside of the arch is flat and transfers load through angled masonry joints.

Joist: A repetitive beam that supports roof or floor loads directly. Wood joists: dimension lumber or engineered lumber used to support a floor or roof. Steel joists: manufactured parallel chord truss used to support a floor or roof.

Joist girder: Steel parallel chord trusses meant to support point loads on panel points.

Joist hanger: A metal device used to connect a wooden joist to an intersecting wood member.

Kip: 1000 pounds (kilo-pound) - a customary US unit.

Knee: In a rigid frame, the beam-column joint.

Lag screw: A large screw with deep threads used to attach to two or more wood members.

Laminated veneer lumber (LVL): Thin wood strips (veneers) glued and compressed together to create a single member.

Lateral-force-resisting system: A structural system used to resist lateral loads. Lateral load: A load associated with wind, seismic, and hydrostatic forces. Ledger: A wooden board attached to the side of a wall to allow for the connection of beams.

Leeward: The side of a building opposite the main wind direction.

Lightweight concrete: Concrete composed of lighter aggregates and more voids compared with normal-weight concrete.

Line of bolts: A regularly spaced group of bolts along the force line of the connected and the connecting parts.

Lintel: A supporting structure used in the construction of a masonry wall to span across openings.

Live load: A load associated with building occupants and objects not permanently attached to the structure.

Load and resistance factor design (LRFD): A method for designing steel structures and structural components.

Load path: The path of resistance to a load.

LRFD: See Load and resistance factor design.

LVL: See Laminated veneer lumber.

Mat foundation: A single, thick reinforced concrete slab used to distribute loads to a larger area of soil.

Microlaminated: See Laminated veneer lumber.

Minipile: Small drilled piles installed in large groups.

Mitre: An angled cut of a member.

Modulus of elasticity: A measure of a material's propensity to deform.

Moment: A force acting through a distance.

Moment of inertia: A geometric quantity that dictates an object's propensity to deform in flexure.

Monolithic concrete: Structural concrete formed in a single placement.

Multiple-pass welding: Welding in which the required weld size is larger than the largest possible weld, so that the weld metal is deposited by parts. 
Nave: The central area of a church for the purpose of congregation.

Nominal size: The dimension as described in a member name, as opposed to the actual size.

OC: See On centre.

Occupancy category: A means of categorising buildings by the function in which they serve.

On centre (OC): Measurement made from the centre of objects.

One-way system: A concrete floor system that transfers load, primarily, in one direction to the supporting members.

Oriented strand board (OSB): An engineered lumber product comprising layers of wood strands in specific orientations, glued and compressed to create a single member.

OSB: See Oriented strand board.

Out of plane: The plane perpendicular to that of an object's strong axis.

Panel (truss): A subdivision of a truss based on the area between vertical members.

Pier: A vertical structural element (normally concrete) used to make a connection between the superstructure and the foundation.

Pilaster: A rectangular column engaged into a wall and projecting from it.

Pile: A pipe, rectangular shape, or I-shape driven into the ground to support the foundation of a building.

Pinned connections: An ideal support condition in which the end of a member is restrained in translation only.

Pinned-pinned: An ideal support condition in which both sides of a member (beam or column) are restrained in translation only.

Platform framing: A method of wood construction in which the floors bear directly on the top of the walls of the level below.

Plywood: An engineered wood product made of thin sheets of lumber glued together in alternating directions.

Podium building: A building that incorporates two distinct structures, generally a heavier structure at the base (steel or reinforced concrete) and a lighter one (wood or cold-formed steel framing) for the remaining superstructure.

Pore water pressure: Water pressure that exists within the gaps between soil particles.

Portal frame: A frame with rigid connections (moment-resisting frame).

Post-tensioned concrete: A type of prestressed concrete in which the steel tendons are stressed after the concrete has been placed.

Pressure-treated timber: A wood product treated before construction to resist decay when subjected to harsh environments.

Prestressed concrete: A type of concrete structure that uses steel strands in tension to pre-compress the concrete.

Pretensioned concrete: A type of prestressed concrete in which the steel tendons are placed in tension before the concrete is placed.

Purlin: Secondary roof members subjected to distributed loads.

Quarry tile: An unglazed stone tile. 
Rafter: An angled member of a pitched roof.

Reaction: The force exerted on a member by the support of a structural member.

Reinforced concrete: Concrete placed with embedded reinforcing bars to increase the capacity.

Reinforced masonry: Masonry strengthened using reinforcing bars, both horizontal reinforcing in the mortar joints as well as vertical reinforcing placed within the voids.

Reinforcement: A strengthening element placed within a material, typically used in concrete and masonry.

Reinforcing steel: Steel used to provide additional strength in either tension or compression in concrete and masonry structures.

Retaining wall: A wall separating two different ground levels.

Rigid: A member resistant to deformation.

Rigidity: The ability of a member or structure to resist deformation.

Rolled steel beams: Structural steel that is formed in rollers while still hot.

Roof deck: Plywood or steel sheets laid on the supports of a roof.

Roof pitch: The angle or slope of a roof.

Row of bolts: A regularly spaced group of bolts perpendicular to the force line of the connected and the connecting parts.

Segmental arch: An arch whose shape is a segment of a half-circle.

Shear diagram: A graph showing the internal shear along the length of the member.

Shear force: An internal force within a member perpendicular to the long axis.

Shear wall: A solid wall used to resist lateral forces applied to a building.

Simply supported: A single span having both supports pinned. See Pinnedpinned.

Skip joist: A reinforced concrete joist with a wider spacing than customary, usually from 5 to $8 \mathrm{ft}$ (1500 to $2500 \mathrm{~mm}$ ).

Slender column: A compression member subjected to buckling to the length/ width ratio of the member.

Snow load: The load due to the build-up of snow. Calculated from the ground snow load.

Span: The distance between supports.

Spandrel beam: See Edge beam.

S-P-F: See Spruce-pine-fir.

Spread footing: Part of the foundation tasked with distributing the load from the columns to the soil below.

Spring line, springing: The level, or point, at which an arch begins to rise above the abutment.

Spruce-pine-fir (S-P-F): A common species group of construction lumber used in the North American building industry.

Steel deck: A thin grooved panel used to support a concrete slab during construction.

Stress: Force per unit area.

Studs: Vertical members connecting the top plate and the sill plate of a wall.

Superimposed dead load: A load that is permanently attached to the structure of the building that is not included in the self-weight. 
Superstructure: The portion of a structure located above the foundation system.

Tensile stress: See Tension.

Tension: The state of stress caused by two opposing outward forces.

Tension lap splice: The connection of two overlapping members.

Thrust: The horizontal force resulting from arch action.

Toe-nailing: A method of connecting two members together by nailing at an angle through the connecting member into the connected member.

Transfer girder: A girder used in place of a column that transfers the load to adjacent columns to allow for an opening.

Tributary width: The width of the floor, wall, or roof that a structural member is responsible for supporting.

Truss: An assembly of members supporting a roof or bridge.

Truss plate: See Gang-nail plate.

Two-way system: A concrete slab system that distributes forces in two perpendicular directions.

Uniformly distributed load: An evenly dispersed load over the entire length or portion of a member.

Unrestrained: Free to translate or rotate.

Uplift: An upward force on a member or structure.

Vibroflotation: A method of compacting soils by introducing vibrations into soil.

Vibroreplacement: Vibroflotation combined with replacement of the native soils.

Wall: A structural or architectural feature dividing two spaces.

Wall footing: The foundation of a load-bearing wall.

Web: The part of a rolled steel structural section that connects two flanges.

Weld: A method of connecting members by fusing weld material between two metal components.

Wide flange beam: A hot-rolled steel section that consists of two flanges separated by a web.

Windward: The side of a building that faces the main wind direction.

Wood I-joists: An engineered wood product consisting of two flanges (usually dimensional lumber) separated by a web (usually oriented strand board).

Wood joist: A wooden member used in the construction of a floor.

Wythe: A single thickness of a masonry unit in a wall. 